\title{
Thermography of Low Energy Buildings
}

\author{
by H. Heinrich and K.-H. Dahlem
}

Universität Kaiserslautern, Bauphysik / Technische Gebäudeausrüstung / Baulicher Brandschutz, PB 3049, D 67653 Kaiserslautern, Germany, E-mail: hheinric@rhrk.uni-kl.de

\section{Abstract:}

In Germany for some years thermography has been used for the detection of critical points in older buildings. With its help the experts become able to localize and judge heat leakages in the form of thermal bridge effects.

In the last years thermography has become popular for the analysis of new buildings, especially "low energy“ or „passive“ houses. Development of new components and quality control are the main purposes in these investigations.

\section{Introduction - Trend of energy consumption of buildings}

Saving energy is one of the most important global challenge in our days. The facts that our ressources are limited and that the use of energy contributes excessive to pollution and to the greenhouse effect are examples for the necessity to act in this field.

In Germany about $75 \%$ of the energy consumption in buildings is used for domestic room heating. In the last 25 years especially triggered by the world wide energy crisis in 1973 wide spread efforts have been made to reduce this energy consumption for heating by better thermal insulation of new built houses.

In the past typical German residentual buildings had a specific yearly energy consumption of about $220 \mathrm{kWh} / \mathrm{m}^{2}$. With the actual standards [1] nowadays the heat losses are reduced to about $60-90 \mathrm{kWh} / \mathrm{m}^{2} \mathrm{a}$. This demonstrates a remarkable reduction but further efforts are necessary.

A comparison with Scandinavian countries for example with Sweden obviously shows that it is possible to achieve still better solutions with acceptable additional costs. Therfore a number of comitted architects and engineers design and build new houses with much less heat losses.

In consequence a remarkable percentage of the new built one family houses are „low energy buildings“ with specific rates of about $50 \mathrm{kWh} / \mathrm{m}^{2}$ a or „passive houses“ with only $30-15 \mathrm{kWh} / \mathrm{m}^{2} \mathrm{a}$. These results can be achieved by very low U-values of the external building envelope of about only $15 \mathrm{kWh} / \mathrm{m}^{2} \mathrm{~K}$. Figure 1 shows the development of reduction of energy consumption for domestic room heating in buildings in Germany.

\section{Thermal bridges}

Thermal bridges are limited areas in the construction where the heat flow is higher than the heat flow in the undisturbed area. One consequence is a lower inner surface temperature. In older buildings this effect causes a damage potential by condensation of water vapour.

The trend in recent years to build low energy buildings leads to a better insulation of external components and therefore to a reduction of transmission heat loss. With good insulation the damage potential because of the low inner surface temperature is quite small compared to older buildings but the relative transmission heat loss 
through thermal bridges is much higher. Therefore the influence of thermal bridge effects becomes more and more important in buildings with low energy technology.

Typical thermal bridges are:

- corners

- embedding of ceilings in the external wall

- embedding of inner walls in the floor to the basement

- embedding of inner walls in the roof / attic

- overhanging balconies or other constructions

- installation of windows in the external wall

Thermal bridges can not be totally prevented. It is only possible to reduce their effects by carefully designed and performed details. By this way a reduction of the heat losses of thermal bridges in comparison to the losses through the undisturbed building envelope is possible of about $20 \%$ for a standard building and of about $30 \%$ of a low energy building [2].

Therefore the impact of thermal bridge effects becomes more and more important in buildings of low energy technology. A lot of efforts are made to keep the thermal bridge effects low. It is necessary to think about details of the building construction.

Normally there were made computer simulations with numerical methods as FE or FD to prove the design and to optimize details.

In reality the construction details often were not built and performed exactly as they were calculated. But in the case of a heated building the quality of these details can be controlled with infrared-thermography because there are great temperature differences if the constructions does not reach the high quality standard. With external thermography an overview can be achieved and with thermography from inside of the building the interesting details can be seen more accurate.

So thermography is a very good tool for the localization and valuation of these thermal bridges.

\section{Numerical simulations and measurements with thermography}

A thermal bridge which exists in every building is the corner. That place was in older buildings often critical because of the low inner surface temperatures. In buildings with a high insulation standard the geometrical effect of this point is the same but the temperature is not longer in a critical range. The situation can be visualized and measured by thermography.

A typical element of low energy buildings in lightweight construction method is the use of I-beams in the structure. An example of such a structure is shown in figure 2 The advantage of such a system in opposition to a full wood structure is a much smaller thermal bridge but there is still an effect nevertheless.

Figure 3 shows a thermogram of such a construction taken from the inside of a building. The low temperature along the beam is obvious to see. For the same construction detail a simulation with the Finite-Elemente-Method was caculated. The relation between the computation and the measurement with the IR-camera of such a construction in a laboratory test is illustrated in figure 4 . The most important problem for the calculation is that the heat transfer into or from the solid due to the surface resistance can only be estimated. That makes a measurement for example with thermography necessary to get correct informations about the surface temperature. 
Another critical point of the building envelope is the penetration of the insulation by anchorages. If it is possible they should be avoided. When they are necessary they must be thermally decoupled from the rest of the construction. A not decoupled penetration shows an increse of the heat loss of about $40 \%$. With a thermal decoupling this increase can be reduced to only $6 \%$ [3].

Figure 5 shows a thermogram taken from the outside of a low energy building. The effect of the penetration of the insulation by anchorages for a railing is to seen as a detail.

\section{Ventilation heat loss}

In contrary to the reduction of the transmission losses in the past by higher insulation standards the ventilation heat losses remained almost at the same absolute level. That expresses that their relative contribution to the total energy consumption of a building increased in the past until nowadays up to $50 \%$ or even more. In order to reduce those too the installation of ventilation systems with heat recovery is necessary. For this purpose the building wrapping should be as dense as possible.

For the definition of the building tightness the Blower-Door method is generally applied. This method of measurement for the inspection of the air tightness and the demands on this are defined in different standards $[4,5,6]$. With the Blower-Door method a rate of the tightness is given. If this rate doesn't keep the required conditions it is necessary to localize the leakages. The straight forward method to localize the leakages is the thermography.

\section{Blower-Door test with thermography}

The Blower Door uses a fan temporarely installed at the front door of the building. With this setup a lower inside air pressure can be produced against the outside air pressure. There the colder outside air will be sucked in through leakages. This results in a temperature decrease at the surface of the building components touched by the cold air. With thermography it is possible to find these temperature decreases and in consequence the leakages very fast so they can be repaired.

Figure 6 shows an indoor thermogram of a corner in a low energy building during a Blower-Door test. Obviously there is to be seen the incoming colder outside air in the corner area and at the sockets.

\section{Conclusion}

Infrared Thermography is not only a useful but also a necessary method to check and control low energy buildings and passive houses just after the finishing. If there are failures which are responsable for higher energy consumption they can be detected and often easily repaired.

\section{References}

[1] Wärmeschutzverordnung, 16.8.1994, Bundesgesetzblatt I p. 2121

[2] POHL,W.-H., et. al.: Niedrigenergiehäuser unter Verwendung des Dämmstoffes Styropor, Bauforschung für die Praxis, Band 31, Stuttgart 1997 
[3] CZIESIELSKI, E.: Wärmebrücken bei Verankerungen hinterlüfteter Außenwandkonstruktionen, Internationaler Bauphysikkongreß, Berlin 1997

[4] DIN V 4108 -7: Wärmeschutz im Hochbau, Teil 7 : Luftdichtheit von Bauteilen und Anschlüssen - Planungs- und Ausführungsempfehlungen sowie -beispiele, Berlin 1996

[5] DIN E 4108 -21: Wärmeschutz im Hochbau, Teil 21 : Außenwände von Gebäuden, Luftdurchlässigkeit, Prüfverfahren, Berlin, 1996

[6] DIN EN ISO 9972 : Wärmeschutz - Bestimmung der Luftdichtheit von Gebäuden, Differenzdruck-Verfahren (Deutsche Fassung : pr EN 9972 : 1996), Berlin 1997

Figures

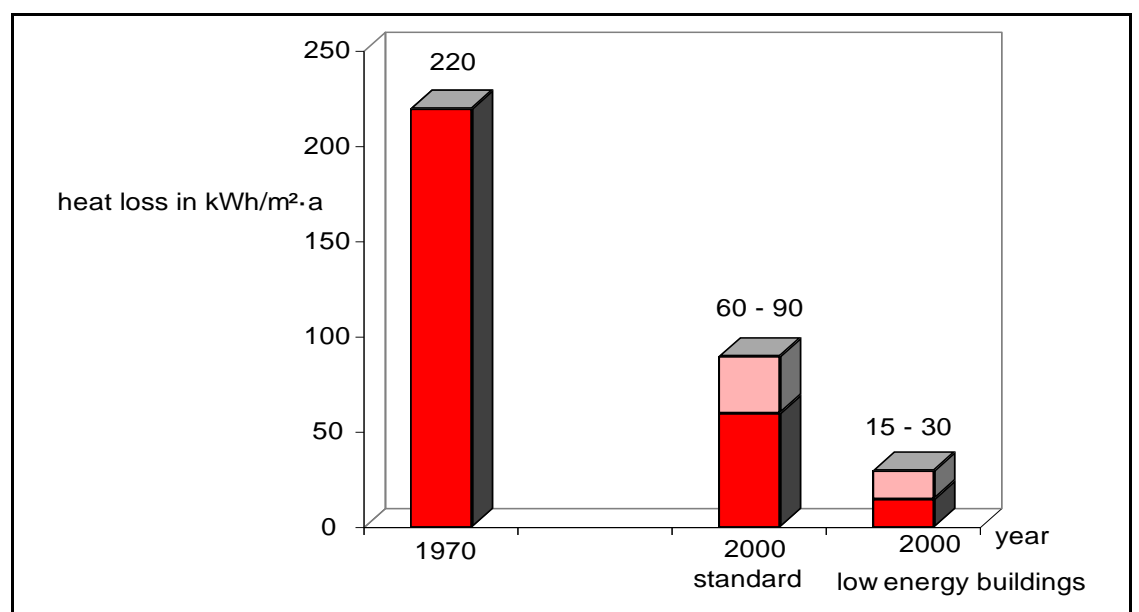

Fig.1. Reduction of energy consumption for domestic room heating in Germany (from 1970 to 2000)

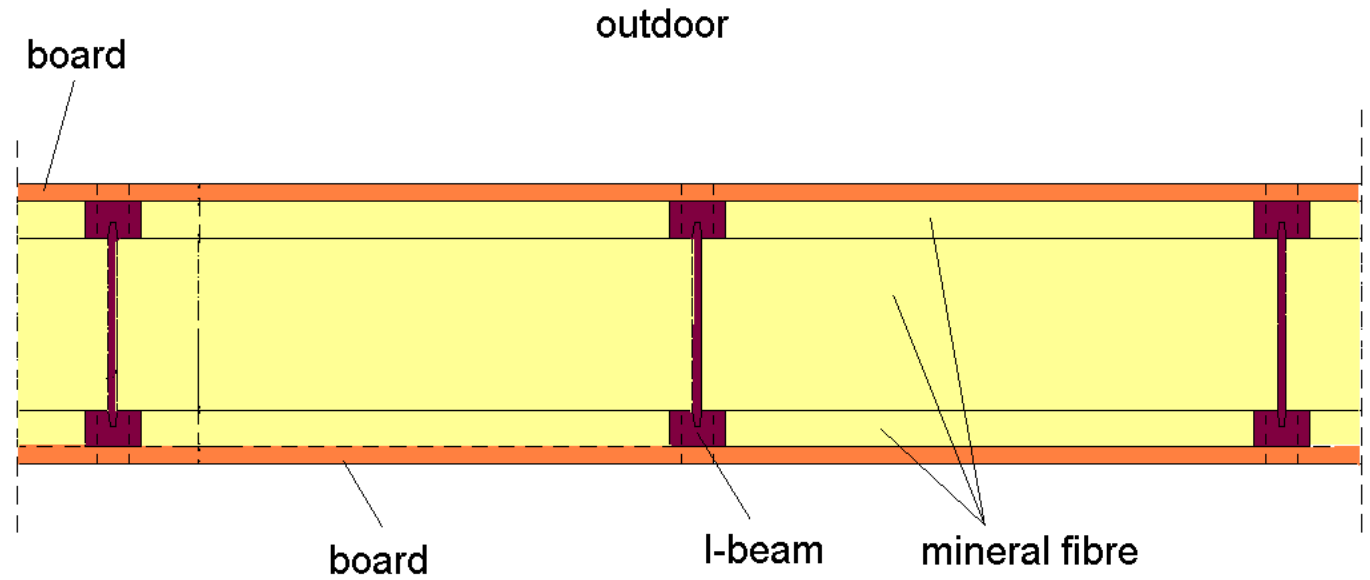

indoor

Fig. 2. Lightweight construction wall in a low energy building 


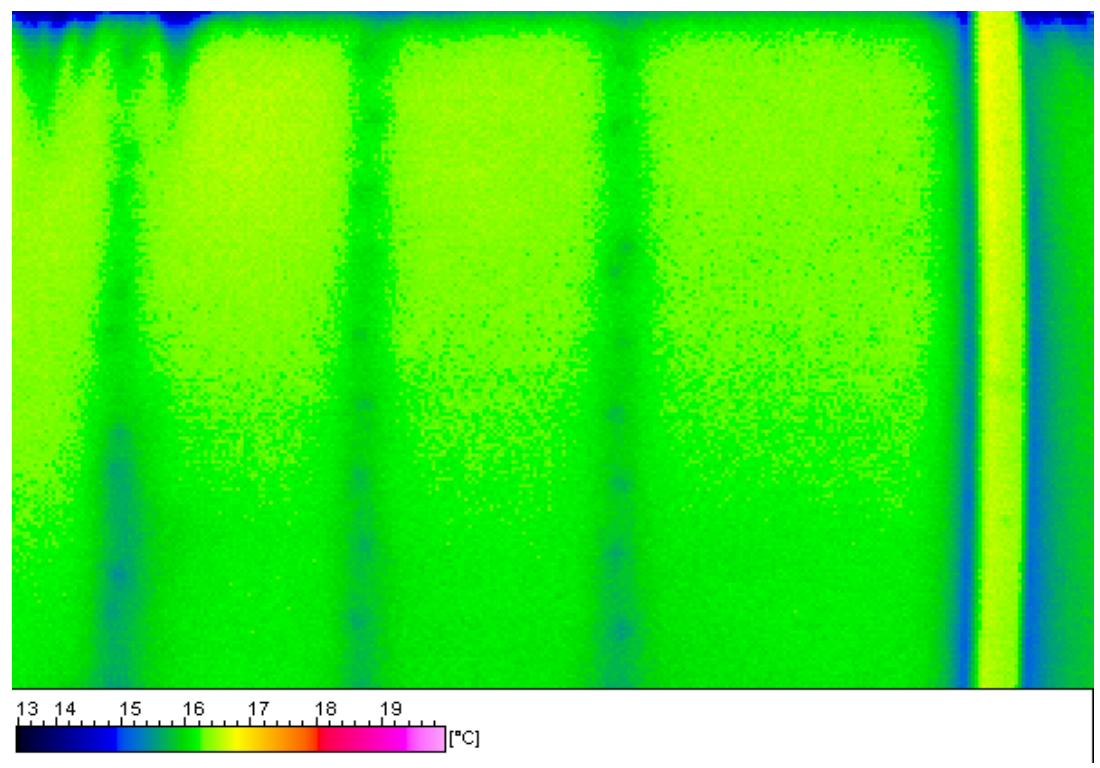

Fig. 3. Thermogram of a lightweight construction wall

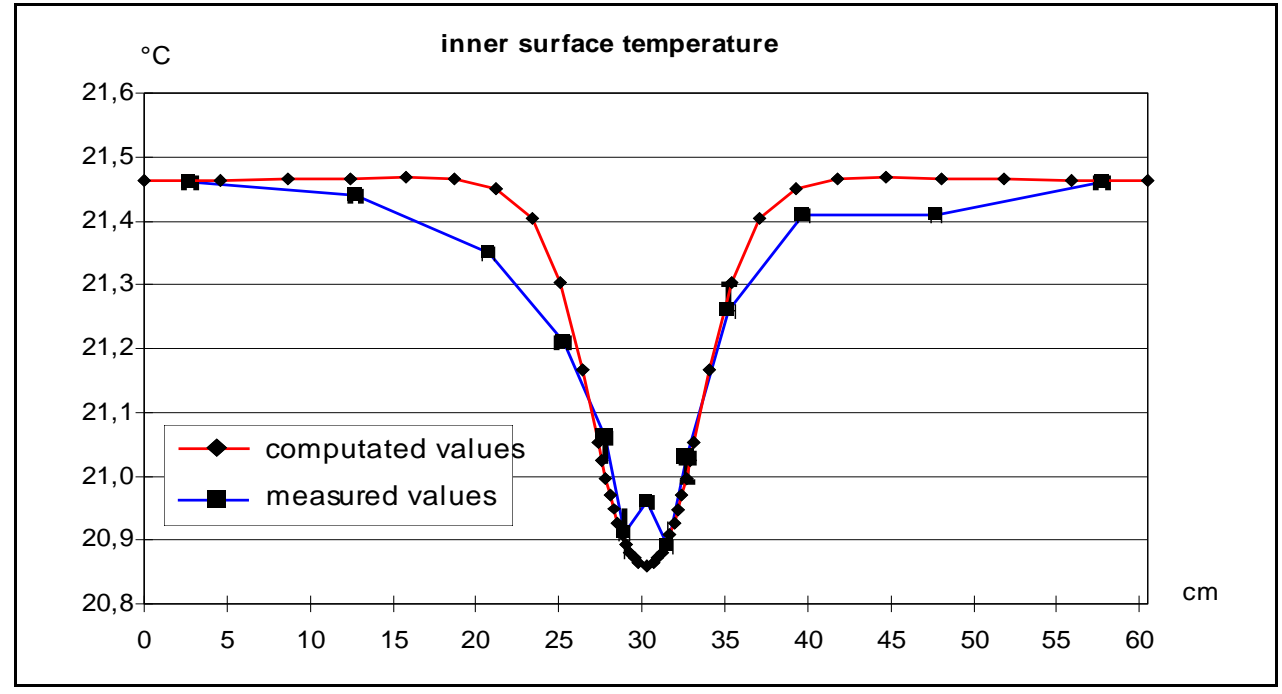

Fig. 4. Computed and measured surface temperatures over the I-beam

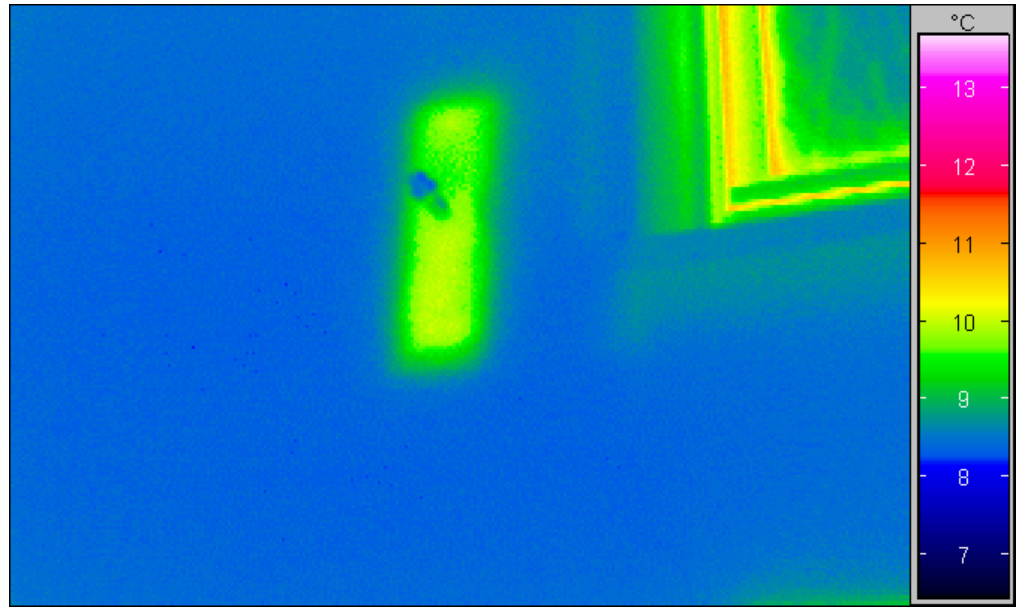

Fig. 5. Thermogram for the anchorage of a railing 
http://dx.doi.org/10.21611/qirt.2000.022

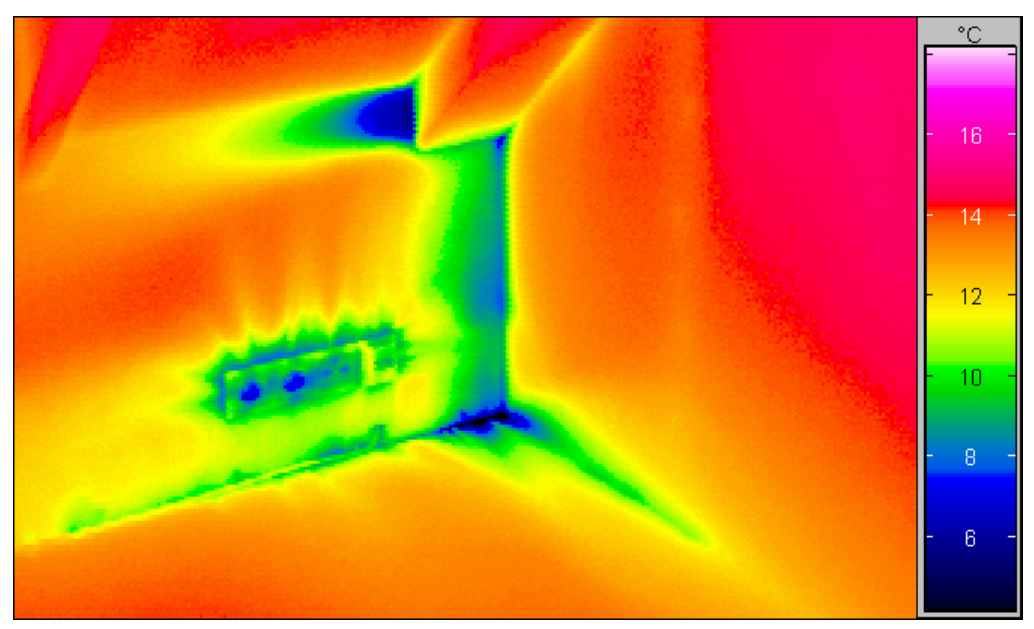

Fig. 6. Thermogram of a corner during blower door test shows air leakages 